\title{
Managing Surprises in Complex Systems: Multidisciplinary Perspectives
} on Resilience

\author{
P. H. Longstaff 1
}

Key Words: resilience

One only need access the news media to become aware of an apparently neverending string of surprises. Some surprises are financial, such as the sharp decline in the U.S. housing and mortgage markets or the increase in the cost of crude oil. Other surprises include the impacts of hurricanes or the collapse of renewable resource stocks. Holling (1986) defined a surprise as "a condition in which perceived reality departs qualitatively from expectations." Many of our 21st Century surprises are a consequence of living in an increasingly connected world that is increasingly complex as well.

These surprises emerge and evolve along many dimensions: political, economic, ecological, biophysical, among others. These disciplinary threads intertwine. Pulling on one of the threads has an effect on many (or all) of the others-often in unpredictable ways. When we find an idea or mechanism that is part of many of these threads, it makes studying these complex systems seem possible. The ideas about resilience so painstakingly developed by the Resilience Alliance and this journal have begun to act as a bridge between many disciplines. The attributes of resilient ecological systems are beginning to be studied in business, political science, emergency management, human physiology, human development, engineering, and many more disciplines. This is a step forward if we are to come to grips with the complex issues such as climate change, global economic systems, security for global infrastructures, and human institutions. All these problems play out in unpredictable environments. But all of the work being done in these many disciplines must be shared and the limits of metaphor explained for each. However, perhaps even before this basic work is completed, the work in progress must be shared with people who can try these ideas to solve the really pressing problems that face us at the global, national, and local levels. Problems that cannot wait for academic certainty.

In just about every call from government or from foundations for research proposals on issues of critical national or global importance, the funder asks for interdisciplinary or multidisciplinary approaches to the problem. There are few people even in the highly fragmented academic world who think that any one discipline has all the answers. And yet the wheels of academic research grind ever more fine within each discipline. And reliable mechanisms for cooperation among disciplines remain illusive. No one who has not worked on a team with people from other disciplines can understand how hard it is. But the challenges that demand this kind of team work and integrated thinking are too big to turn away from just because the task will not be easy.

In 2006, a grant from the National Science Foundation brought together 12 people who study "resilience" in ecology, computer science, immunology, human development, communications, and computer science. Their task was to try to find common ground. At first they did not know how to talk to each other. But the more they talked, the more they could see that bridges might be possible. They agreed to collaborate on this special issue of Ecology and Society and bring their ideas about resilience to a larger audience-where other people may see the possible bridges. In 2008, three of them presented a panel at the Resilience Conference in Stockholm to share their ideas. These are small steps in the agenda discussed above but they, and the steps taken in similar experiments around the world, prove that a multidisciplinary study of resilience 
is not impossible. The next steps must be bigger and bolder. Missteps will also most certainly be made. It is not a journey for the faint of heart, and the ultimate destination is far from certain. But in science and all important human endeavors it was ever thus.

Responses to this article can be read online at:

http://www.ecologyandsociety.org/voll4/iss 1/art49/responses/

\section{LITERATURE CITED}

Holling, C. S. 1986. The resilience of terrestrial ecosystems; local surprise and global change. Pages 292317 in W. C. Clark and R. E. Munn, editors. Sustainable Development of the Biosphere. Cambridge University Press, Cambridge, UK. 